\title{
Considerations for Canister Design and Drop Testing
}

\author{
Brian Hawkins
}

January 2019

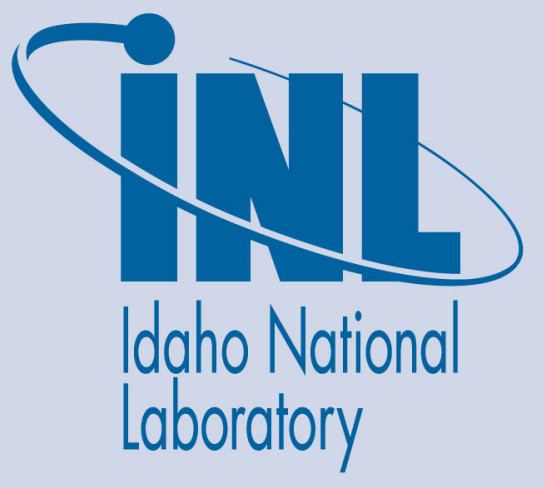

The INL is a U.S. Department of Energy National Laboratory operated by Battelle Energy Alliance 


\title{
Considerations for Canister Design and Drop Testing
}

\author{
Brian Hawkins
}

January 2019

Idaho National Laboratory Idaho Falls, Idaho 83415

http://www.inl.gov

Prepared for the

U.S. Department of Energy

Under DOE Idaho Operations Office

Contract DE-AC07-05ID14517 


\title{
Considerations for Canister Design and Drop Testing
}

\author{
Brian Hawkes
}

\section{Introduction}

This paper discusses some considerations for the proposed design and analysis of canisters used to ship reactor debris from the Fukushima Daiichi nuclear plant.

Energy-limited events, such as cask drops and other dynamic impacts, are evaluated much differently than other structures using static analysis. Static analysis of structures makes sense for engineers because static analysis is intuitive and material typically behaves in a linear elastic manner. Dynamic analyses are typically not intuitive because of non-linear material behavior. This is why canister designs need to be evaluated by dynamic finite element analysis and/or laboratory drop tests.

\section{Dynamic Drop Analysis Issues}

Failure of energy-limited events is most accurately predicted using non-linear strain-based failure rather than stress-based failure. Using stress-based failure will result in very conservative canister designs. It is predicted that approximately 50,000 canisters will be used in this project to store the debris from the nuclear plant. Therefore, it is desired to reduce expenses by making the canisters robust enough to meet the drop requirements without making them too conservative.

The energy absorbed by the material in the canister is the area under the true-stress true-strain curve. Very ductile materials, such as 316L, can absorb a lot of energy since the dynamic strain at failure is very high. The amount of energy absorbed by a specific material depends on factors such as the material temperature and the instantaneous strain rate.

Currently, there is no consensus standard for performing drop tests or dynamic drop analysis using finite element modeling. Therefore, canisters need to be designed using good engineering practices and evaluated by using competent analysis techniques and/or drop tests.

\section{Drop Orientations}

A canister needs to be evaluated for the drop orientations that result in the most severe damage to the canister. Since the canister orientation at impact is usually unknown, the following impact orientations are typically used to evaluate the canister impact on a flat rigid surface to envelope all possible cases:

- Flat bottom

- Canister center of gravity $(\mathrm{cg})$ oriented vertically over the bottom corner

- Flat side

- Canister cg located vertically over the top corner

- Flat top

- Slap down drop where the axis of the canister forms an angle of about 10 degrees with the plane of impact and the bottom corner strikes the impact surface first

- Any other orientations of interest such as impact on trunnions or other features

It will simplify the analysis if some of these drop orientations can be removed because the canister simply cannot be dropped in that orientation.

Previous experience shows that the when the canister is fabricated from a very ductile material, such as austenitic stainless steel, that the flat bottom and bottom corner drops produce damage, but rarely cause failure that could result in a breach of the canister with the bottom corner drop producing the most damage. Drops that challenge the bolts that attach the lid to the canister are more likely to cause a canister breach due to bolt failure. The top corner and slap down drops are typically the most challenging to the lid bolts. 
A flat top and top corner drop usually have an extra impact from the contents on the inside of the lid. After the initial canister impact on the rigid surface in one of these two orientations, the contents (in this case, the cans) will be accelerated toward the impact surface and will slam into the underside of the lid, which could cause tensile failure of the lid bolts.

\section{Modeling the Canister Contents}

There are two types of analyses that are typically performed to evaluate a canister drop.

1. Model the contents as very stiff where they do not absorb much energy to produce the worst case for the canister.

2. Model the canister as very stiff so that it does not absorb much energy to produce the worst case for the contents.

In the case of using the canister to transport reactor debris, the amount of energy absorbed by the debris in the cans is largely unknown. Therefore, it is recommended that the contents be conservatively modeled as stiff objects, such as steel bars, to produce the worst loads for the canister.

\section{Lid Bolts}

The lid bolts are the most likely point of failure in a canister drop and should be evaluated in as much detail as necessary to determine if and how they fail.

The design of the canister should ensure that the bolts are loaded only in tension. All shear loads on the bolts should be eliminated by the canister design. All lateral loads, which could produce shear loads in the lid bolts, should be absorbed by other structures of the canister. If necessary, the bolt holes in the lid should be enlarged so the lid can move laterally without imparting shear loads to the bolts.

The specified pre-load on the lid bolts should be adequate to prevent leakage from the canister but the lid bolts do not typically need to be tightened to the maximum.

\section{Dual Certified Materials}

In the past, 316 or $316 \mathrm{~L}$ materials were ordered for specific needs depending on whether more strength was needed or the low carbon content was needed for welding. In recent years, dual stamped or dual certified materials have been used in the United States. These materials meet the alloy requirements of 316 and $316 \mathrm{~L}$, the minimum strength requirements of 316 and the low carbon requirements of $316 \mathrm{~L}$. This material is stamped with $316 / 316 \mathrm{~L}$ and is used for both 316 and $316 \mathrm{~L}$ applications. For more information, please see The American Society of Mechanical Engineers, Boiler and Pressure Vessel Code, Section II Part D, Mandatory Appendix 7.

It would be beneficial to use this dual stamped material because it gives you the higher strength of 316 and the weld ability of $316 \mathrm{~L}$ and could reduce the cost of producing the canisters.

\section{Welds}

Any welds used in the fabrication of the canister should meet the weld specifications. It is recommended that only full penetration welds be used to fabricate the canister. Partial penetration welds, such as fillet welds, have a built-in crack initiator and rapidly fail in cask drops.

\section{Issues With Scaled Model Drop Tests}

Scaled model tests using linear elastic material properties and stress-based failure work well and are intuitive for engineers. Scaled models used in drop analysis need to address some additional issues that may not be intuitive for engineers. 
- Failure in energy-limited events is determined by the amount of energy absorbed per unit volume of the material. For a scaled model drop, the energy absorbed per unit volume should match the energy absorbed per unit volume of a full size model.

- If a model is scaled to $1 / 3$ of a full size model, all parts of the scaled model, including the wall thicknesses, should be $1 / 3$ of the size of the full sized model.

- Since the scaled model has $1 / 3$ of the material to absorb energy and 1/3 of the mass of the full sized model, the scaled model should be dropped from the same height as the full sized model to produce the same energy per unit volume of material for both models.

- Since the energy absorbed is also dependent on the strain rate of the material, it should be ensured that the material strain rate is the same for the scaled model drop test and the full sized model drop test.

Scaled model drop tests are very good at helping to evaluate a canister design, but a full size drop test is necessary to confirm that the canister final design will not breach.

\section{About the Author}

Brian Hawkes spent 29 years working at the Idaho National Laboratory as a Mechanical Engineer. He has a bachelors and masters degree in Mechanical Engineering. He spent 24 years working in the Applied Mechanics group performing stress analysis, which included analyzing nuclear shipping casks using Abaqus Finite Element models for dynamic drop analysis. Information discussed in this paper has come from years of analyzing nuclear shipping cask drops. 